\title{
Hypofractionated radiotherapy to treat acne keloidalis nuchae
}

\author{
Jennifer Yin Yee Kwan MD, May Tsao MD, Elizabeth A. Barnes MD
}

Cite as: CMAJ 2021 October 18;193:E1595. doi: 10.1503/cmaj.210307
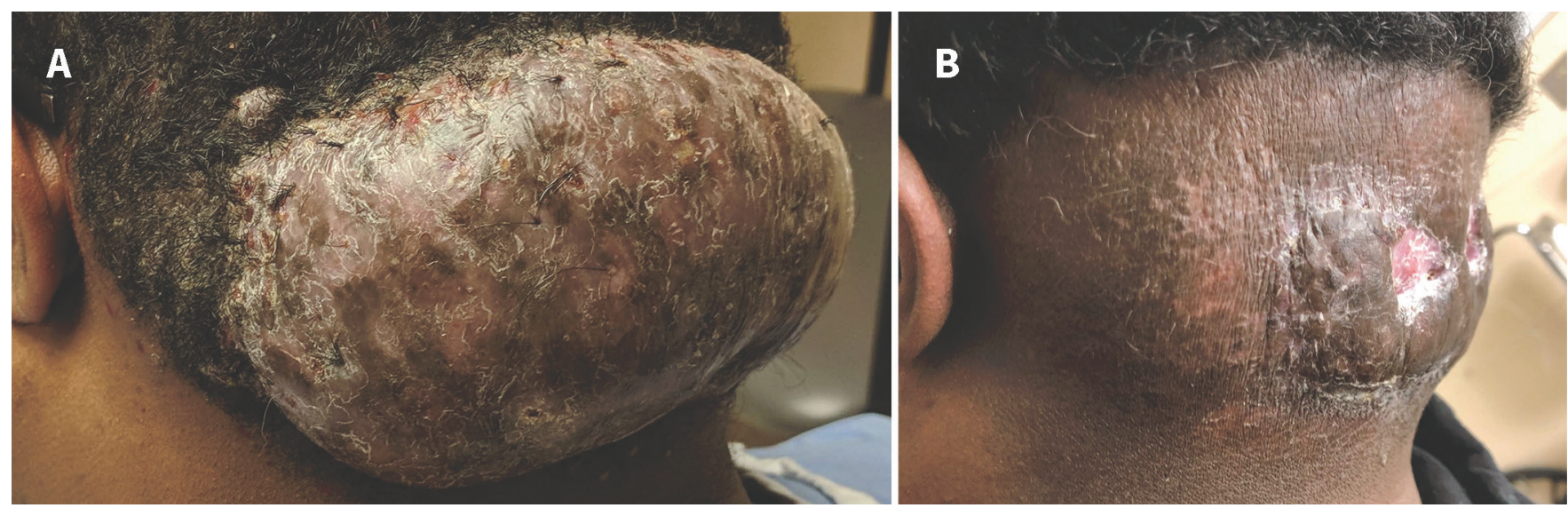

Figure 1: Photographs showing the appearance of acne keloidalis nuchae at the nape of the neck of a 27-year old man of African descent (A) before radiotherapy and (B) 1 year after radiotherapy.

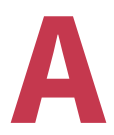

27-year-old man of African descent presented to our radiotherapy clinic with a 5-year history of a recurrent $15 \times 8 \times 4 \mathrm{~cm}$ keloidal tumour (i.e., acne keloidalis nuchae) on his posterior neck (Figure 1A). Previous treatments of systemic isotretinoin, antibiotics and surgical excision without adjuvant radiotherapy were unsuccessful, and he was ineligible for re-excision given the size of the lesion. Because he was troubled by the appearance of the lesion, he minimized social contact, which also affected his ability to work.

He underwent definitive radiotherapy using volumetric modulated arc therapy (35 Gy in 5 weekly fractions), with the goal of reducing the keloidal tumour size. After radiotherapy, he required regular wound care during the regression of the lesion. He had no recurrence at 19 months (Figure 1B).

Acne keloidalis nuchae is a chronic inflammatory disorder initiated by hair follicle injury, resulting in keloid papules and plaques. ${ }^{1}$ It occurs almost exclusively in people of African descent, predominantly men (20:1). ${ }^{2}$ Estimates of prevalence, including mild-to-severe presentations, range from $0.5 \%$ to $13.6 \% .^{2}$ Acne keloidalis nuchae is diagnosed clinically without biopsy, and mild presentations can be treated with steroids, retinoids or antibiotics. ${ }^{2}$ Laser and light therapy can be used to reduce the number or size of lesions. ${ }^{2}$ For fibrotic or persistent lesions, excision may be helpful; ${ }^{2}$ however, surgery alone is associated with a higher rate of recurrence. ${ }^{3}$ Adjuvant steroids or radiotherapy may reduce the risk of recurrence, but must be balanced against risks. ${ }^{4}$

Acute adverse effects of radiotherapy include skin erythema, desquamation, wound dehiscence and infection, ${ }^{4}$ whereas late effects include skin pigmentation changes, telangiectasia, fibrosis, alopecia and a threefold increased risk of secondary malignant growth in the treated area. ${ }^{4,5}$ The incidence of radiotherapy-related adverse skin effects is greater than $50 \% .^{4}$

\section{References}

1. Salami T, Omeife H, Samuel S. Prevalence of acne keloidalis nuchae in Nigerians. Int J Dermatol 2007;46:482-4.

2. Ogunbiyi A. Acne keloidalis nuchae: prevalence, impact, and management challenges. Vol. 9. Clin Cosmet Investig Dermatol 2016;9:483-9.

3. Maranda EL, Simmons BJ, Nguyen AH, et al. Treatment of acne keloidalis nuchae: a systematic review of the literature. Dermatol Ther (Heidelb) 2016;6:363-78.

4. Speranza G, Sultanem K, Muanza T. descriptive study of patients receiving excision and radiotherapy for keloids. Int J Radiat Oncol Biol Phys 2008;71:1465-9.

5. Lichter MD, Karagas MR, Mott LA, et al. Therapeutic ionizing radiation and the incidence of basal cell carcinoma and squamous cell carcinoma. Arch Dermatol 2000;136:1007-11.

\section{Competing interests: None declared.}

This article has been peer reviewed.

The authors have obtained patient consent.

Affiliations: Department of Radiation Oncology (Kwan, Tsao, Barnes), University of Toronto; Department of Radiation Oncology (Tsao, Barnes), Odette Cancer Centre, Sunnybrook Health Sciences Centre, Toronto, Ont.
Content licence: This is an Open Access article distributed in accordance with the terms of the Creative Commons Attribution (CC BY-NC-ND 4.0) licence, which permits use, distribution and reproduction in any medium, provided that the original publication is properly cited, the use is noncommercial (i.e., research or educational use), and no modifications or adaptations are made. See: https://creativecommons.org/licenses/by-nc-nd/4.0/

Correspondence to: Elizabeth Barnes, toni.barnes@sunnybrook.ca 